\title{
Diagnóstico dos agroecossistemas da Microbacia Hidrográfica Mariana no Território Portal da Amazônia, Mato Grosso, Brasil $^{1}$
}

\author{
The agroecosystems diagnosis of the Mariana \\ Hydrographic Microbasin in the Amazonia Portal \\ Territory, Mato Grosso State, Brazil
}

Delmonte Roboredo ${ }^{a}$ Sônia Maria Pessoa Pereira Bergamascob

Wagner Gervazio ${ }^{c}$

aProfessor Efetivo no curso de Agronomia, área de Extensão Rural, Universidade do Estado do Mato Grosso, Alta Floresta, MT, Brasil. End.Eletrônico: roboredo@gmail.com

${ }^{b}$ Professora Visitante Nacional Sênior do Programa de Pós-Graduação em Agroecologia e Desenvolvimento Rural da Universidade Federal de São Carlos, Campus Araraquara, Araraquara, SP, Brasil. End.Eletrônico: sonia@feagri.unicamp.br

'Doutorando em Engenharia Agrícola, Faculdade de Engenharia Agrícola (Feagri), Universidade Estadual de Campinas, Campinas, SP, Brasil End. Eletrônico: wagnergervazioengagro@gmail.com

doi:10.18472/SustDeb.v8n1.2017.18840

Recebido em 20.05.2016

Aceito em 09.02.2017

ARTIGO - VARIA

\section{RESUMO}

A abertura de novas fronteiras agrícolas na década de 1970, como o caso de Alta Floresta, Mato Grosso, estimulada pelo governo federal, ocorreu sem a preocupação com a preservação das florestas e contribuiu para a geração de fortes externalidades negativas. Este trabalho tem por objetivo realizar o diagnóstico socioambiental da Microbacia Hidrográfica Mariana localizada no município de Alta Floresta, Mato Grosso. A pesquisa foi realizada dentro do enfoque sistêmico por meio de entrevistas semiestruturadas e análises físicas dos solos. Os resultados obtidos identificaram que $78,6 \%$ dos entrevistados compraram suas propriedades nos anos 1980/1990, dos quais $84 \%$ informaram que não foram orientados para preservação das matas ciliares e $93 \%$ dos entrevistados responderam ter interesse em recuperar as áreas degradadas, mas faltam-lhes condições financeiras. 0 estudo aponta que aquele território está degradado social e ambientalmente em virtude de que $74,5 \%$ dos solos dos agroecossistemas pesquisados apresentaram macroporosidade menor que $10 \%$; falta da participação social, além da forte evasão rural que compromete a reprodução social.

Palavras-chave: Agricultura Familiar. Degradação Socioambiental. Políticas públicas. Extensão Rural. 


\section{ABSTRACT}

The opening of new agricultural frontiers in the 70s, as it happened in Alta Floresta, Mato Grosso, was stimulated by the federal government and took place without any concern for the preservation of forests, thus contributing to the generation of strong negative externalities. This work aims to carry out a socioenvironmental diagnosis of the Mariana Hydrographic Microbasin of the municipality of Alta Floresta, in the Mato Grosso State of Brazil. The systemic approach employed for this research included the use of semi-structured interviews and the soil physical analysis.. Results indicate that $78.6 \%$ of respondents had bought their properties in the $80 / 90$ s. Of that percentage, $84 \%$ respondents reported that they had not received any orientation regarding the preservation of riparian forests, and $93 \%$ answered that while they did had an interest in recovering degraded areas, they lacked the necessary financial resources to implement such a recovery. The study also points out the social and environmental degradation of the territory, showing, among other indicators, that $74.5 \%$ of the soils of the researched agroecosystems presented macroporosity of less than 10\%; a marked lack of social participation, and a strong flow of rural migration that compromises the possibility of social reproduction.

Keywords: Family Farming. Environmental Degradation. Public Policy. Rural Extension.

\section{INTRODUÇÃO}

O município de Alta Floresta faz parte de um projeto de colonização dirigida conduzido pela Colonizadora Indeco S.A. na década de 1970, que recebeu enormes incentivos governamentais. Durante esse período, o governo federal, liderado pelo Presidente da República, Emilio Garrastazu Médici, adotou o slogan "integrar para não entregar" com a justificativa de que era necessário proteger a floresta amazônica contra a internacionalização (SILVA JÚNIOR, 2006). Essa política de incentivo foi a indutora mais importante para a substituição das florestas pelas atividades agropecuárias (ARRAES et al., 2012), impulsionada pelo processo da revolução verde, gerou enormes externalidades negativas em várias regiões, como, por exemplo, o Território Portal da Amazônia².

Segundo a Agenda 21 Local de Alta Floresta, os agroecossistemas do município encontram-se com $56 \%$ das áreas de preservação permanente (APPs) com elevado grau de degradação, assim como os aspectos sociais e econômicos revelam a precariedade das condições de vida local. Com relação aos recursos naturais, os solos perderam sua fertilidade natural elevando o nível de compactação devido ao aumento da densidade do solo ocasionado pelo pisoteio excessivo, proporcionando condições favoráveis ao escorrimento superficial e assoreamento dos recursos hídricos, contribuindo para a perda da qualidade dos solos e das águas (ALTA FLORESTA, 2008).

Dessa forma, o processo degradativo dos agroecossistemas, além de afetar os recursos naturais, também provoca a perda do poder de compra das famílias rurais, estimulando uma forte migração rural-urbana da população mais pobre. Esse fluxo gera uma forte pressão sobre a infraestrutura urbana, contribuindo para a queda na qualidade de vida das famílias nos grandes centros, devido ao desemprego ou aos subempregos decorrentes de outros impactos negativos, resultando na degradação do ser humano (BARRIOS; DESCROIX, 2010).

Os agroecossistemas são sistemas complexos por contemplar diferentes classes de solos; multiplicidade de aspectos culturais (saberes e crenças locais), os projetos de vida das famílias; segurança alimentar; atividades agrícolas e não agrícolas; os meios de produção existentes (insumos, tecnologia e equipamentos) e a relação com os recursos naturais. Assim, é imprescindível a adoção do enfoque sistêmico no estudo dos agroecossistemas conforme defende Gallopín (2003, p. 7), "El enfoque sistémico puede proporcionar una perspectiva más útil que otros métodos analíticos, debido a que es una manera de reflexionar en función de conexiones, relaciones y contexto." O enfoque sistêmico requer uma visão abrangente, bem como a interação do trabalho de pesquisas com extensionistas e agricultores, para que possam caminhar rumo à sustentabilidade dos agroecossistemas. 
Nesse contexto, este estudo objetiva avaliar a degradação socioambiental, bem como a percepção das famílias rurais diante do processo de recuperação das áreas de preservação permamente dos agroecossistemas da Microbacia Hidrográfica Mariana no município de Alta Floresta, Mato Grosso. Para tanto, foi empregado o enfoque sistêmico na busca da interação de fatores que contemplam a complexidade do rural. Com com base nesses fatores, defende-se a tese de que esse ambiente encontra-se degradado social e ambientalmente.

\section{2 ÁREA PESQUISADA E PARÂMETROS METODOLÓGICOS}

A pesquisa foi desenvolvida na Microbacia Hidrográfica Mariana, localizada no município de Alta Floresta, que possui uma área de $8.947 \mathrm{~km}^{2}$ e uma população de 49.164 habitantes. Desse total, $42.718(86,9 \%)$ residem na zona urbana e 6.446 pessoas (13,1\%) na área rural (IBGE, 2010). Ainda, de acordo com o IBGE (2006), no município há 2.317 estabelecimentos agropecuários, dos quais $78 \%$ são explorados por agricultores familiares (BRASIL, 2006); ocupam apenas 18\% da área de 535.321 ha, enquanto $22 \%$ dos estabelecimentos encontram-se nas mãos de agricultores não familiares.

\subsection{POR QUE A MICROBACIA HIDROGRÁFICA MARIANA COMO ÁREA DE ESTUDO?}

A escolha da MBM deve-se ao fato de ela ser a fonte de captação de água que abastece a cidade de Alta Floresta e pelo importante papel na recarga dos rios Taxidermista, Telles Pires e, por sua vez, o Rio Tapajós, responsável pela alimentação do sistema aquífero Alter do Chão (ZOBY; OLIVEIRA, 2005). Esse território também foi cenário da assinatura do Termo de Ajustamento de Conduta (TAC) para recuperação das APPs promovido pelo promotor de Justiça da Comarca de Alta Floresta devido à forte supressão das matas ciliares.

A pedido do Ministério Público Estadual, Umetsu (2009) efetuou um amplo levantamento da MBM que gerou o Quadro 1 sobre as classes de uso e ocupação das terras da MBM, onde pode-se ver que não há exploração econômica voltada para agricultura, mas somente pastagem destinada à bovinocultura de leite e corte.

Quadro 1 - Classes de uso e cobertura da terra da MBM em Alta Floresta-MT.

\begin{tabular}{|l|c|c|}
\hline \multirow{2}{*}{ Classes de Uso } & \multicolumn{2}{|c|}{ Área } \\
\cline { 2 - 3 } & $\mathbf{( k m}^{\mathbf{2}} \mathbf{~}$ & Percentual (\%) \\
\hline Áreas úmidas & 2,25 & 3,45 \\
\hline Floresta & 15,68 & 24,05 \\
\hline Floresta degradada & 1,60 & 2,45 \\
\hline Pastagem & 39,91 & 61,22 \\
\hline Vegetação arbustiva & 2,19 & 3,36 \\
\hline Água & 1,45 & 2,22 \\
\hline Solo exposto & 2,2 & 3,25 \\
\hline Total & 65,28 & 100 \\
\hline
\end{tabular}

Fonte: Umetsu (2009).

\subsection{COLETA DE DADOS}

Nesse trabalho o estudo convergiu para algumas variáveis (atributos físicos do solo, reprodução social, aspectos ambientais, organização social, políticas públicas para recuperação das APPs) consideradas importantes para avaliar a degradação socioambiental da MBM. A pesquisa baseou-se em dados secundários oriundos de diversos trabalhos (relatórios, artigos e cadastro ambiental rural) realizados 
na MBM, bem como na coleta de dados primários por meio de entrevistas semiestruturadas. 0 objetivo foi conhecer a percepção dos agricultores sobre os aspectos socioambientais, por meio de um questionário que foi ajustado na forma de pré-teste para adequá-los à realidade local, segundo recomendação de Richardson et al. (1999). Coletou-se também amostras de solos para conhecer os atributos físicos e identificar o nível de compactação dos solos da MBM.

A avaliação dos solos dos agroecossistemas foi realizada em duas áreas contíguas: área de preservação permanente (APP) e no seu entorno ${ }^{3}$ (ENT). A análise dos atributos físicos (macroporosidade, porosidade total e densidade do solo) seguiu a recomendação da Embrapa (1997) estudando duas camadas, 0,0$0,20 \mathrm{~m}$ e $0,20-0,40 \mathrm{~m}$. Para a resistência mecânica do solo à penetração (RMSP) foi realizada até a profundidade de 0,50 $\mathrm{m}$ utilizando um penetrômetro de impacto baseada em Stolf (1991), cujos resultados foram estratificados em camadas de $0,10 \mathrm{~m}$. A amostragem ocorreu nos meses de outubro e novembro de 2011.

Nas entrevistas utilizou-se o registro oral com gravador digital para facilitar a obtenção dos dados e ampliar a garantia das informações obtidas, principalmente no que tange às frases empregadas pelos entrevistados para expressar suas satisfações e insatisfações. Ressalta-se que as gravações foram efetuadas com a devida autorização dos entrevistados por reconhecê-los como sujeitos do processo e seguindo orientação de Meihy e Ribeiro (2011). O diagnóstico também adotou o pensamento de Rodriguez et al. (2008, p. 23) que destacam "El papel de los investigadores es de diagnóstico y facilitación. No intentan imponer decisiones, es um processo participativo basado em la voluntad y la negociación".

A transcrição da fala dos entrevistados baseou-se em Meihy e Ribeiro (2011, p. 109) os quais sugerem que "palavras ou expressões repetidas, como 'né', 'sabe', 'então', 'daí por diante' e 'depois disso', sejam mantidas em dose suficiente para o leitor sentir o tipo de narrativa ou o sotaque".

Na definição do total de famílias amostradas adotaram-se os preceitos de Tompkin ${ }^{4}(1967$, p. 55) que recomenda "quando somente o número de itens na população é importante, a variância não é necessária" e ainda que "uma amostra de 50 observações é geralmente mínimo". Assim, quando o universo amostral for menor do que 5.000, Tompkin (1967) recomenda amostragem "com 50 indivíduos acrescido de mais $2 \%$ do total da população". Desse modo, foram entrevistadas 56 famílias (Figura 1) cujos estabelecimentos foram separados em quatro extratos de área (até 50 ha; 50 a 100 ha; 100 a 150 ha; e >150 ha), para manter a fração ótima e assegurar a representatividade dos diversos agroecossistemas conforme orientação de Richardson et al. (1999).

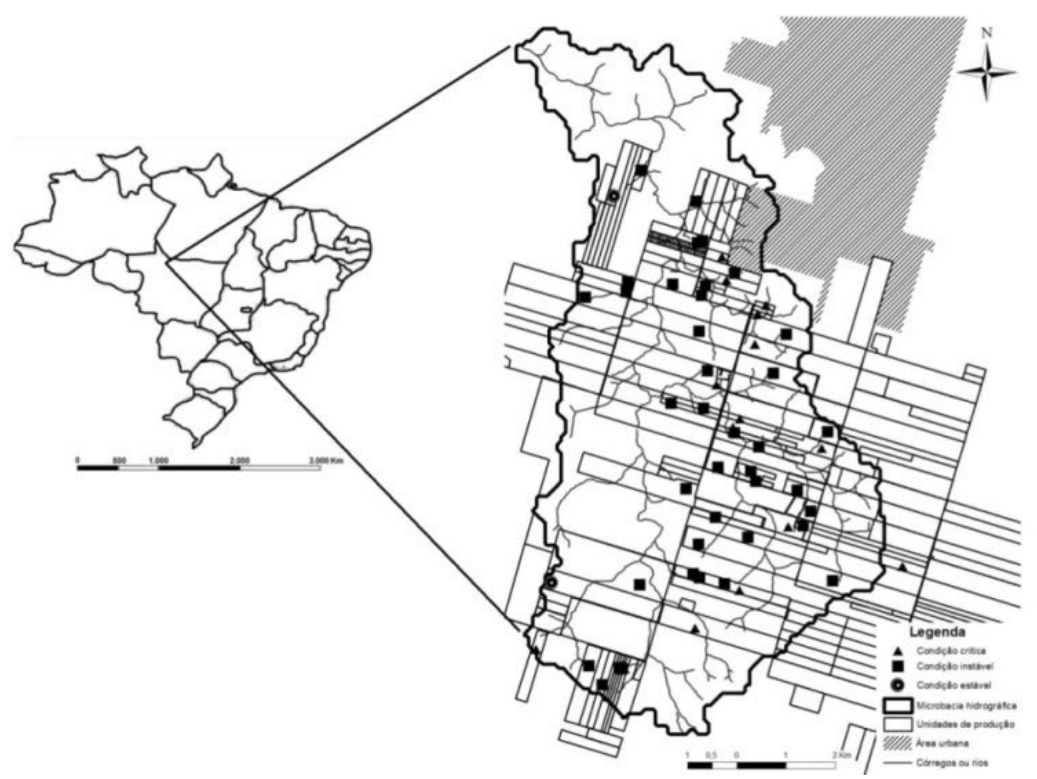

Figura 1 - Localização e distribuição espacial dos agroecossistemas na MBM, em Alta Floresta-MT. 


\section{RESULTADOS E DISCUSSÃO}

Os resultados obtidos são oriundos de $62,5 \%$ de agricultores familiares em conformidade com os requisitos da Lei 11.326 (BRASIL, 2006). Todavia, apesar de todos os entrevistados terem área menor que quatro módulos fiscais (400 ha), vários $(37,5 \%)$ não atendem aos demais requisitos da lei para se enquadrarem como agricultores familiares (renda, mão de obra e gestão da propriedade). A área média pesquisada dos agroecossistemas foi de 54,7 ha, tendo como área mínima 1,20 ha e máxima de 254,1 ha. Todos os entrevistados detêm o domínio legal dos imóveis rurais.

\subsection{CARACTERIZAÇÃO FÍSICA DOS SOLOS DA MBM}

Pelos resultados da Tabela 1, visualiza-se que a maioria dos solos apresenta baixa macroporosidade $(<10 \%)$ e com significativo CV (coeficiente de variação) na segunda camada da APP $(50,71 \%)$ e na área do entorno (52,81\%). Sendo que em $21 \%$, aproximadamente, os macroporos ( $\geq 50 \mu \mathrm{m}$ ) eram maiores ou iguais a $10 \%$ e menores do que $15 \%$. Apenas em cinco estabelecimentos foram encontradas macroporosidade ideal ( $>=15 \%$ ). Porosidade com ar abaixo de $10 \%$ é, de maneira geral, considerada restritiva ao crescimento radicular e, consequentemente, à produtividade da maioria das plantas, apesar da dependência da espécie de planta e da atividade biológica do solo (GIAROLA et al., 2007).

Tabela 1 - Valores medianos dos atributos físicos dos solos da MBM, em Alta Floresta-MT.

\begin{tabular}{|c|c|c|c|c|}
\hline \multirow{2}{*}{ Medidas de dispersão } & \multicolumn{2}{|c|}{ APP } & \multicolumn{2}{|c|}{ ENT } \\
\hline & $0-0,20 \mathrm{~m}$ & $0,20-0,40 \mathrm{~m}$ & $0-0,20 \mathrm{~m}$ & $0,20-0,40 \mathrm{~m}$ \\
\hline \multicolumn{5}{|c|}{ Macroporosidade } \\
\hline Mediana (\%) & 7,53 & 6,63 & 7,84 & 8,13 \\
\hline CV (\%) & 41,88 & 50,71 & 37,44 & 52,81 \\
\hline \multicolumn{5}{|c|}{ Porosidade Total } \\
\hline Mediana (\%) & 39,88 & 40,67 & 42,96 & 45,02 \\
\hline $\mathrm{CV}(\%)$ & 11,22 & 28,03 & 10,95 & 18,07 \\
\hline \multicolumn{5}{|c|}{ Densidade } \\
\hline Mediana $\left(\mathrm{Mg} \mathrm{m}^{-3}\right)$ & 1,59 & 1,60 & 1,54 & 1,46 \\
\hline CV (\%) & 15,50 & 21,95 & 16,69 & 22,20 \\
\hline \multicolumn{5}{|c|}{ Resistência mecânica do solo à penetração } \\
\hline Mediana (MPa) & 2,02 & 2,60 & 1,98 & 2,55 \\
\hline CV (\%) & 28,28 & 29,81 & 32,99 & 24,75 \\
\hline
\end{tabular}

Onde: $\mathrm{CV}=$ coeficiente de variação (\%); ENT= área do entorno.

Fonte: Elaborado pelos autores.

A porosidade total (PT) que representa o somatório da microporosidade e macroporosidade dos solos deve atingir valores igual ou maior a $50 \%$ na capacidade de campo, sendo $33,5 \%$ ocupado pela água e 16,5\% pelo ar (REICHART et al., 2007). Vê-se na Tabela 1 que os valores medianos da PT estão entre $39 \%$ e $45 \%$. Ao analisar a PT dos estabelecimentos pesquisados, diagnosticou-se que a maioria $(56,5 \%)$ dos solos está com a PT entre $40 \%$ e $50 \%$, seguido de $33,3 \%$ dos solos com PT menor que $40 \%$ de poros totais, enquanto que apenas $8 \%$ apresentam PT maior do que $50 \%$.

É possível verificar que $100 \%$ dos solos da camada de 0,20-0,40 m da APP e as duas camadas do ENT ficaram com a densidade entre 1,1 e 1,5 $\mathrm{Mg} \mathrm{m}^{-3}$, enquanto que $78 \%$ da camada de 0-0,20 m da APP apresentou elevada densidade $\left(>=1,5 \mathrm{Mg} \mathrm{m}^{-3}\right.$ ), $20 \%$ oscilaram de 1,1 até $1,5 \mathrm{Mg} \mathrm{m}^{-3}$ e $2 \%$ dos solos nessa camada não foram possíveis amostrar devido à forte presença de cascalhos. 
A variabilidade dos coeficientes de variação (CV) contida na Tabela 1 deve-se ao fato de que os atributos foram pesquisados em diferentes estabelecimentos agropecuários que, por sua vez, contêm heterogeneidade de classes de solos que vêm sendo manejados de diferentes formas pelos agricultores contribuindo para obtenção de variados valores dos atributos físicos. Resultados semelhantes foram encontrados por Ceconi (2010) em pesquisa realizada sobre os impactos da pressão antrópica na mata ciliar da microbacia hidrográfica do Vacacaí-mirim, Santa Maria/RS, onde encontrou CV que variaram de $16,9 \%$ a $39,7 \%$.

E, por último, avaliou-se a compactação através da RMSP onde obtiveram-se valores medianos de 2,00 MPa na primeira camada e de 2,58 MPa na segunda camada.

Para melhor visão da RMSP no perfil do solo elaborou-se a Figura 2 com os dados medianos dos estabelecimentos investigados em camadas de 0,10 $\mathrm{m}$ até a profundidade de 0,50 m. Nota-se na Figura 2 que na primeira camada os valores médios são bem semelhantes (1,42 e 1,47 MPa). Entretanto, a RMSP aumenta de forma expressiva na camada de 0,10-0,20 m, passando para 2,46 MPa (ENT) e 2,53 MPa (APP), mantendo-se esse comportamento médio nas camadas subsequentes, alcançando 2,73 $\mathrm{MPa}$ (APP). Acredita-se que o aumento nas camadas subsuperficiais deve-se à forte presença de cascalho e plintitas nas áreas estudadas, principalmente nas APPs.

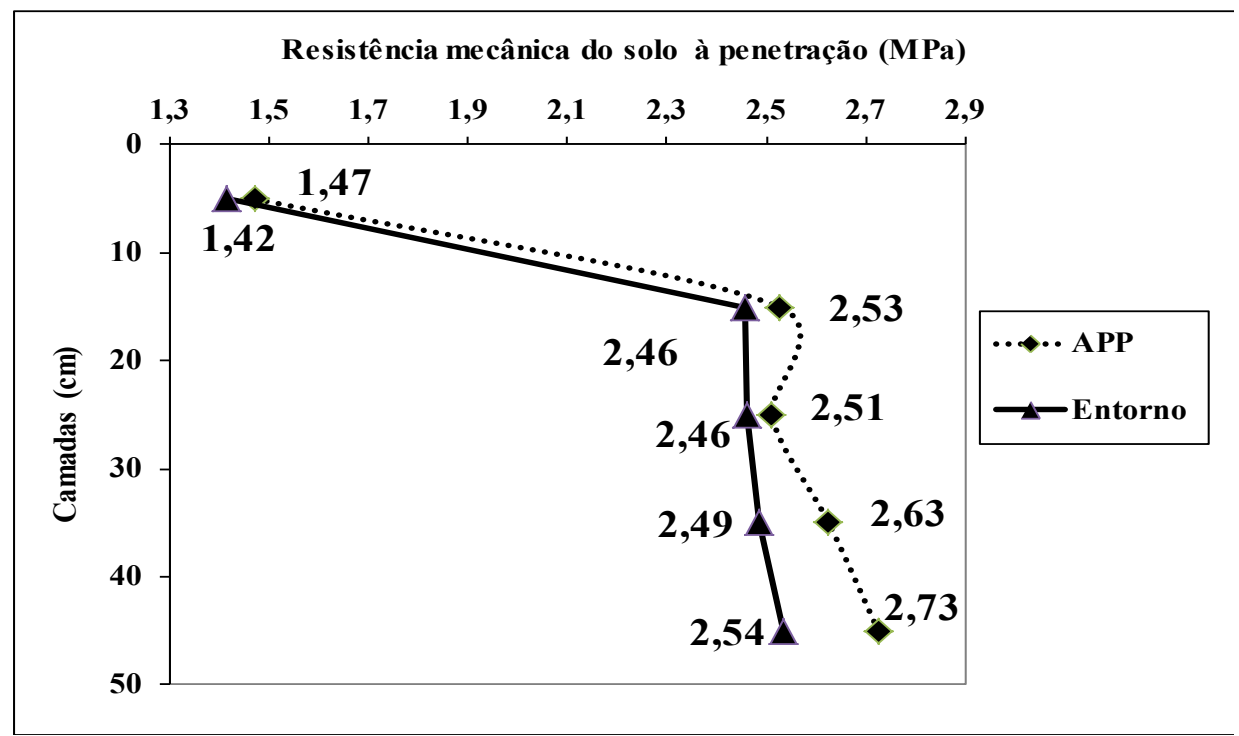

Figura 2 - Resistência mecânica do solo à penetração na MBM, em Alta Floresta-MT.

Fonte: Elaborado pelos autores.

Depreende-se pelos resultados obtidos que os solos da MBM encontram-se degradados, de maneira geral, devido à predominância de média e alta compactação diagnosticadas nos estabelecimentos pesquisados, considerando que: i) $74,5 \%$ dos solos em ambas as áreas (APP e ENT) e camadas apresentam macroporosidade < do que $10 \%$; ii) em $56,5 \%$ dos solos a porosidade total está entre $40 \%$ e $50 \%$ de poros total, ou seja, pelo critério adotado, são considerados solos mediamente compactados. O quadro se agrava, pois a PT em $33 \%$ dos solos amostrados estão com poros totais inferiores a $40 \%$, ou seja, altamente compactados; iii) em $78 \%$ dos solos da camada de $0-0,20$ m apresentaram densidade superior a 1,5 $\mathrm{Mg} \mathrm{m}^{-3}$; e iv) 64,8\% dos solos estão com a RMSP maior do que 2,5 e menor ou igual a 5 MPa. Os parâmetros utilizados estão baseados em Reichert et al. (2007) e Petean et al. (2010).

Estudo realizado por Oliveira et al. (2000), na Bacia Hidrográfica do Rio Ivinhema/MS, consta que a ocupação desordenada da bacia implicou em grandes alterações na paisagem natural, ocasionadas pelo desmatamento, destruição das matas ciliares, erosão dos solos, assoreamento e contaminação dos mananciais, entre outros danos ambientais e sociais de grande intensidade. 


\subsection{REPRODUÇÃO SOCIAL}

O entendimento de reprodução social adotado neste trabalho segue o conceito do sociólogo Bourdieu (1974) que destaca esse fenômeno como um processo pelo qual as culturas são reproduzidas por meio das gerações. Em outras palavras, esse processo representa a continuidade das famílias rurais no campo, condição sine qua non para a continuidade dos movimentos sociais, desconcentração da terra, e da biodiversidade. A reprodução social das famílias nesse ambiente é preocupante devido à grande evasão que vem ocorrendo, ocasionada por diversos fatores (baixo preço da produção, descrédito nas políticas públicas, evasão dos jovens para os centros urbanos à procura de estudo e emprego, entre outros). Tais problemas constituem as principais causas para a degradação social das famílias, visto que a maioria absoluta dos agroecossistemas vem sendo conduzidos somente pelos pais.

Tal assertiva pode ser visualizada na pirâmide etária (Figura 3) das famílias entrevistadas, constituída por 89 pessoas ( 47 do sexo masculino e 42 do sexo feminino), indica a existência de poucos jovens na faixa etária entre 15 e 29 anos morando nas propriedades rurais (sete do sexo masculino e oito do sexo feminino), enquanto que $51 \%$ das pessoas que compõem as famílias têm idade superior a 50 anos ( $31 \%$ de homens e $20 \%$ de mulheres). Esse cenário demonstra a forte migração dos jovens para a cidade, ficando nas unidades produtivas somente as pessoas com idade avançada para conduzir atividades econômicas, predominantemente, de pecuária de leite e corte. Essa situação é preocupante, principalmente porque até o presente momento não há projetos consistentes que estimulem o retorno dos jovens às suas propriedades. E, por consequência, a reprodução social torna-se difícil com a ausência de crianças e jovens na MBM.

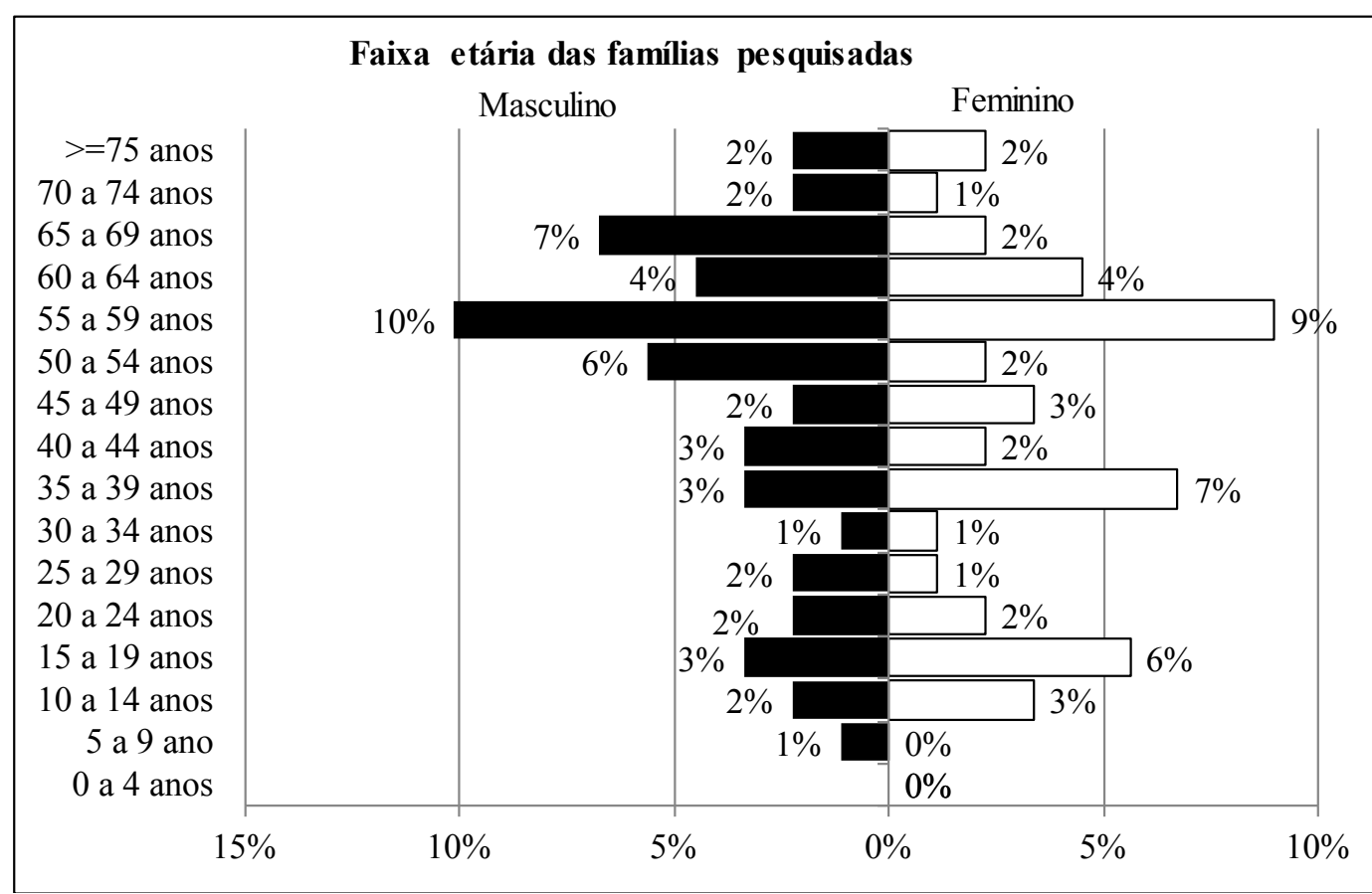

Figura 3 - Pirâmide etária das pessoas que moram e trabalham nos estabelecimentos rurais da MBM, em Alta Floresta-MT.

Fonte: Elaborado pelos autores.

Cabe ressaltar que muitos desses jovens gostariam de voltar para o campo se houvesse políticas públicas que contribuíssem para a obtenção de resultados positivos, ou seja, retorno econômico justo para terem acesso às necessidades básicas para seu sustento e lhes permitissem a reprodução social com uma vida digna. Esse contexto representa o pensamento da maioria absoluta dos entrevistados que está contido na fala do jovem filho do agricultor C34 que disse "gostaria de ficar na propriedade, pois é bom morar no campo junto com os pais, mas não há apoio [políticas públicas]", como, por exemplo, o crédito rural para as pequenas propriedades. Apesar do Programa Nacional de Fortalecimento da Agricultura Familiar (Pronaf) ser uma excelente opção, o agricultor tem muita dificuldade de acessá-lo devido à burocracia. 
O cenário da MBM constitui o retrato dos espaços rurais de uma maneira geral, pois o esvaziamento do meio rural deve-se às condições desfavoráveis de vida das famílias rurais devido à

precariedade das condições de acesso aos bens e serviços coletivos básicos, da escassez ou empobrecimento dos recursos naturais disponíveis, a excessiva concentração da estrutura fundiária e da distância e a dificuldade de acesso aos mercados. (WANDERLEY, 2009, p. 306).

\subsection{OCUPAÇÃO DE ALTA FLORESTA E OS MOTIVOS DA SUPRESSÃO DAS MATAS CILIARES}

A ocupação do rural no município de Alta Floresta ocorreu dentro da visão antropocêntrica, na qual a maioria absoluta dos atores sociais (técnicos dos governos Municipal, Estadual, Federal, empresas privadas e agricultores), envolvidos nesse processo, entendiam que a supressão das matas, inclusive das APPs, não prejudicaria o equilíbrio ambiental, visto que a natureza se recuperaria normalmente. Obviamente, esperava-se que pelo menos os profissionais responsáveis pelo serviço público de Assistência Técnica e Extensão Rural (Ater) orientassem os agricultores da importância do cumprimento da legislação ambiental.

A partir desse pressuposto, os entrevistados foram indagados se receberam orientação dos técnicos da Empresa de Assistência Técnica e Extensão Rural do Estado de Mato Grosso (Emater-MT), da Comissão Executiva do Plano da Lavoura Cacaueira (Ceplac), da Secretaria Municipal de Agricultura (Sagri), como órgãos responsáveis pela orientação aos agricultores quanto à preservação das APPs no período compreendido entre o início da abertura do município até os anos 1990. Dos 44 agricultores entrevistados, que tinham estabelecimentos agropecuários no período pesquisado, 37 (84\%) responderam que não haviam recebido nenhum tipo de orientação.

A imparcialidade da pesquisa é condição sine qua non para se apurar a veracidade dos fatos. Nessa linha de pensamento foi consultado o ex-coordenador Regional da Emater (hoje Empaer - Empresa Mato-grossense de Pesquisa, Assistência e Extensão), engenheiro-agrônomo GH (ex-coordenador Regional da Empaer, agrônomo GH, no período de 1980 à 2000) para saber como era a orientação sobre a preservação das matas ciliares, que afirmou: "nunca foi orientado, na época não se falava nisso, não se falava em ambientalismo".

A falta de preocupação quanto à preservação da floresta, no período referenciado, é reforçada pela atitude do próprio órgão de fiscalização ambiental (IBDF, hoje Ibama) que não realizava ações para orientar e/ou fiscalizar as derrubadas, com destaque para as áreas das APPs, segundo informação da maioria dos entrevistados. Ao consultá-los sobre a atuação do Instituto Brasileiro de Desenvolvimento Florestal (IBDF), à época, 75\% responderam que não receberam informações sobre a preservação das APPs, $9 \%$ responderam que sim e $16 \%$ não lembravam ou não quiseram se manifestar.

Todavia, segundo os agricultores C7 e C48, ocorreram casos de fiscalização pelo IBDF. Entretanto, havia uma forte pressão política sobre as autoridades estaduais e federais para que as multas aplicadas não fossem executadas para não desmotivar a permanência e/ou vinda de novos agricultores para Alta Floresta. Caso contrário, a ocupação do município e região ficaria comprometida, devido ao efeito dominó que geraria, refletindo negativamente na venda de terras. Obviamente que o não cumprimento da legislação ambiental não era do interesse somente da colonizadora, mas também das autoridades governamentais que queriam ocupar a região amazônica. Nessa ótica, Alta Floresta constituía excelente porta de entrada para ocupação do extremo norte do estado de Mato Grosso, sul do Pará e Amazonas, para garantir a soberania nacional (BECKER, 1998).

Outro ponto que contribuiu para a derrubada das matas ciliares foi a cultura dos agricultores provenientes do centro-sul do país conforme relata o agricultor C48: "o pessoal que veio do Paraná, o costume dele era derrubar na beira da água pra fazer a casa na beira da água porque tem água ali, já era um costume de lá de fora".

Várias lógicas foram apontadas por outros agricultores para derrubarem as APPs, entre elas destacamse o incentivo dos governos (Municipal, Estadual e Federal) para abertura e ocupação da região (23\%) e 
espantar mosquito da malária ${ }^{5}$ (54\%), entre outras. O agricultor C7 relata que: "era cultura do Paraná, onde todo mundo derrubou, o mosquito sumia [...] era informação da colonizadora [Indeco S.A]".

\subsection{ORGANIZAÇÃO SOCIAL DAS FAMÍLIAS DA MBM}

A organização social inexiste naquele território, predominando entre os agricultores uma atitude individualista, fato que tem dificultado o poder de barganha na compra de insumos, venda da produção e baixo peso político nas reivindicações para: acessibilidade ao crédito rural, serviços de Ater, melhorias da trafegabilidade nas estradas durante todo o ano, entre outros.

Tal afirmação está respaldada nos resultados das entrevistas onde detectou-se que 89,3\% e 91,1\% não participam, respectivamente, do Sindicato dos Trabalhadores Rurais e Sindicato Patronal. Mesmo comportamento se aplica às Associações e Cooperativas, cujos entrevistados responderam que não participam de Associações (96,4\%) e nem de Cooperativas (92,9\%).

Quadro semelhante de desorganização social foi diagnosticado por Abreu et al. (2011), trabalhando com 23 famílias da Microbacia Hidrográfica Riacho da Igreja no município de Cabeceiras na mesorregião de Borborema, na Paraíba, que identificaram como sendo de $100 \%$ o grau de degradação da organização social das famílias. Os autores concluíram que: "a comunidade não dispõe de uma organização que intermedeie melhorias de forma articulada com o poder público, prescindindo de estímulo e de capacitação na busca dessa articulação" (ABREU et al., 2011, p. 28).

Estudo realizado por Bernasconi et al. (2016, p. 67) difere dos obtidos na pesquisa, pois mantiveram a resiliência dos sistemas produtivos, após superar as crises econômicas, devido à "capacidade de organização política do setor em escala nacional que permitiu que os produtores tivessem apoio político, econômico e se mantivessem atualizados localmente sobre os rumos das políticas econômicas federais e estaduais por meio do Sindicato Rural local".

Dessa forma, para superar o individualismo presente na MBM é imprescindível o fortalecimento das famílias rurais por meio da união e da organização conforme ressalta Olival (2016, p. 102) ao concluir seu trabalho sobre resiliência em assentamentos rurais: "uma condição essencial para que haja uma agricultura de base familiar fortalecida é o fortalecimento das próprias comunidades rurais".

Nessa corrente de pensamento Abramovay et al. (2010, p. 276), em seu trabalho sobre participação e movimentos sociais com relação ao empoderamento das organizações na redução da pobreza no campo, ressaltam que sem a participação social as "chances de vitória na luta contra a pobreza são reduzidas".

\subsection{RECUPERAÇÃO DAS APPS: PERCEPÇÃO DOS AGRICULTORES}

A questão ambiental é vista pelos agricultores da MBM como um problema a ser resolvido para melhorar o meio em que vivem. Essa assertiva baseia-se no fato de que $92,9 \%$ dos entrevistados responderam que têm interesse em recuperar as matas ciliares, enquanto que $7,1 \%$ responderam que não.

Vários foram os motivos que levaram os agricultores a demonstrarem interesse em recuperar as matas ripárias. Para tanto, nas frases a seguir espelham o sentimento da maioria dos agricultores $(92,9 \%)$ favoráveis à recuperação e à preservação das APPs: "beira de rio tem que ser revegetada para deixar de herança para os netos [...] antes da Secretaria [Secma] começar já falava para o pai deixar as matas na beira do rio para não desbarrancar" (agricultor C2) e "hoje não derrubaria mais porque a mata na beira do rio é importante" (agricultor C52).

Contudo, ainda há agricultores que entendem o contrário, conforme estudo realizado por Neumann e Loch (2002), como agricultores no litoral norte fluminense que têm a concepção de que a floresta significa um estorvo à prática econômica. 


\subsection{COMO OS AGRICULTORES PERCEBEM A RECUPERAÇÃO AMBIENTAL DA MBM?}

As famílias dos agricultores, mais do que ninguém, conhecem sua condição socioeconômica, assim como o estado dos recursos naturais dos agroecossistemas. Assim, na pesquisa, procurou-se entender "por quê?" eles consideram importante a construção de curvas de nível. Eis uma das respostas que representam o pensamento da maioria dos entrevistados:

a curva de nível é interessante. Porque, por exemplo, você faz uma ideia, olha como povo fala em fazer a cerca beirando o rio para não entrar o gado para beber água no rio, mas agora tá no pasto urina, esterco tudo. Dá uma chuva, para onde vai? Vai lavando pro rio, né? [...] porque com a curva de nível [...] a vitamina da terra vai ficando na terra, né? Porque a terra vai beber aquela água, ali na curva, né? [...] a vitamina da terra fica na terra, não vai pro rio, né? (AGRICULTOR C42).

Foi com esse olhar dos agricultores que procurou-se saber quais atividades deveriam ser realizadas para recuperação dos recursos hídricos e dos solos. Segundo eles, a recuperação ambiental da MBM precisa da implantação de um projeto de microbacia hidrográfica como os realizados nos estados do Paraná e São Paulo conforme expressão do genro do agricultor C18:

Na região de Umuarana-PR, foi feito o trabalho todinho com a prefeitura. O solo lá mudou, era um solo lavado aquela coisa, tá uma diferença incrível o solo [...] o solo melhorou muito. Então aqui, isso aqui era pra tá começando já, ter começado a tempos atrás, tem que ser feito! Isso aqui tem terra muito inclinada, então tem que ser feito!

Na ótica dos agricultores, essas práticas conservacionistas contribuirão diretamente para a contenção da erosão dos solos e, consequentemente, do assoreamento dos rios e mananciais. Esse conhecimento empírico dos agricultores respalda-se em Franzluebbers (2002), o qual destaca que nos solos em que não há curvas de nível e/ou terraços, principalmente em terrenos declivosos, há o favorecimento à lavagem dos solos pela água das chuvas carreando a matéria orgânica e empobrecendo os solos no decorrer do tempo.

A matéria orgânica do solo, segundo Costa et al. (2013, p. 1855), "desempenha um papel importante na sustentabilidade agrícola, influenciando os atributos fisícos, químicos e biológicos do solo, com reflexo na estabilidade da produtividade dos agroecossistemas". Rodriguez et al. (2008) ressaltam que "el mejoramiento de los agroecosistemas comienza por el suelo".

\subsection{QUALIDADE DA ÁGUA NA MBM SEGUNDO OS AGRICULTORES}

$\mathrm{Na}$ expectativa de se avaliar a qualidade das águas dos rios da MBM, foi perguntado aos agricultores se utilizariam a água do rio/córrego de sua propriedade para beber. A maioria absoluta $(83,9 \%)$ dos entrevistados respondeu que não, enquanto que $16,1 \%$ disseram sim.

Os agricultores informaram que não utilizariam água dos rios para beber por estarem contaminadas por fezes de capivaras e bovinos, bem como devido à morte desses animais que atolam e morrem nos rios. Essa realidade pode ser compreendida mais facilmente no pronunciamento de duas famílias: "tenho até receio de entrar nessa água [...] devido a sujeira por capivaras mortas" (agricultor C26).

tem nascente aqui cristalina, mas ainda não dá coragem, porque a erosão é muita, a água da chuva, não tem uma curva de nível pra segurar aquela água, então é uma erosão, é uma lama podre que tá ali, então é difícil (GENRO DO AGRICULTOR C18).

A contaminação dos recursos hídricos é atestada por Merten e Minella (2002), que enfocam que no ciclo hidrológico as chuvas precipitadas ocasionam o escoamento superficial que transporta os dejetos dos animais e poluentes (agrotóxicos) para a rede de drenagem contaminando os rios.

\subsection{INSTRUMENTOS DE APOIO À PRODUÇÃO AGROPECUÁRIA}

Os serviços de Assistência Técnica e Extensão Rural pública constituem excelente política de governo para trabalhar e orientar os agricultores nos diversos estágios das atividades agrícolas e não agrícolas praticadas nos estabelecimentos familiares, sobretudo quando são realizados em conformidade com 
os preceitos da Política Nacional de Assistência Técnica e Extensão Rural - Pnater (BRASIL, 2010) que defende a adoção do enfoque sistêmico e uma Ater construtivista e empoderadora (FREIRE, 1980).

Desse modo, procurou-se saber dos agricultores se recebiam algum tipo de assessoria técnica e/ou os serviços de Ater. Apenas um agricultor informou que recebia acompanhamento dos técnicos das casas comerciais que vendiam os insumos. Todos os demais $(97,7 \%)$ não eram atendidos pelos serviços de Ater pública (Sagri, Empaer e Ceplac) e/ou privada do município.

Ato contínuo, indagou-se sobre o interesse em receber o serviço de Ater disponível na cidade, sendo que $80,4 \%$ responderam que sim, pois, seguramente, os auxiliaria na melhoria da condução das atividades praticadas em suas propriedades; $16,1 \%$ não se mostraram interessados em receber esses serviços e 3,5\% não responderam.

O crédito rural também constitui importante instrumento de política pública para proporcionar condições ao desenvolvimento rural sustentável. Assim, procurou-se saber dos entrevistados se eles receberam financiamento agropecuário no período de 2000 a 2011. Pelas informações obtidas, 11 agricultores $(19,6 \%)$ contraíram financiamento nesse período, enquanto que $45(80,4 \%)$ não obtiveram financiamento, apesar de várias tentativas.

Uma parcela expressiva dos entrevistados $(44,6 \%)$ tem procurado os agentes financeiros, em especial, - Banco do Brasil, para obter financiamentos, mas tem encontrado muitas dificuldades devido à burocracia, conforme eles relataram.

O crédito agropecuário constitui importante ferramenta para fixação da família no campo, sobretudo as linhas do Pronaf destinadas aos agricultores familiares e altamente subsidiadas. Como exemplo pode-se citar o caso da família do agricultor C55 que já tinha desanimado do pedido de financiamento liberado um ano após o pleito. Esse financiamento contribuiu para a melhoria de qualidade e condição para que a família permanecesse no campo conforme expressão da esposa do agricultor C55:

não aguentava mais, estava com os braços, as costas doendo [...] estava pensando até quando íamos aguentar [...] já estava pensando em ir para cidade [...] tínhamos que acordar todos os dias as quatro da manhã, agora podemos dormir um pouquinho mais [...] economizamos mais ou menos duas horas de trabalho.

Estudos realizados por Bernasconi et al. (2016, p. 62) destacam a importância do crédito agropecuário para o fortalecimento do setor rural, pois com o "acesso ao crédito agrícola, há melhoria no grau de beneficiamento da produção, aumenta a produtividade da propriedade, e o escoamento da produção é facilitado, a viabilidade econômica do setor será melhorada". Além do mais, segundo Abramovay et al. (2010, p. 298), os agricultores pagam seus créditos pontualmente constituindo "um forte indicador de que os recursos contribuem para fortalecer sua capacidade de geração de renda".

\subsection{POLÍTICAS PÚBLICAS PRATICADAS NA MBM}

Alta Floresta deu importante passo na recuperação ambiental do município e, consequentemente, da MBM por meio do Decreto n. 4.073 (ALTA FLORESTA, 2011), mediante a elaboração do Cadastro Ambiental Rural (CAR), georreferenciamento das propriedades, e fornecimento de: $50 \%$ de lascas de teca (13.000 dúzias), arames (1.900 bolas de $500 \mathrm{~m}$ ) para cercar as APPs e mudas para reflorestamento. Essas ações foram realizadas com recursos do Fundo Amazônia do Banco Nacional de Desenvolvimento Econômico e Social.

Essas ações foram aprovadas por $80 \%$ dos agricultores, enquanto que $10,9 \%$ não as consideraram relevantes e 9,1\% não souberam opinar ou preferiram não se manifestar. $O$ destaque para o elevado nível de aprovação do trabalho da Secma deve-se ao CAR e ao georreferenciamento realizado por esta, pois a maioria dos agricultores não teria condições financeiras para cobrir os custos desses serviços estimados em $\mathrm{R} \$ 11.500,00$ por propriedade.

Entretanto, na contramão da avaliação positiva está o peso negativo da má qualidade das lascas de teca entregues aos agricultores na primeira fase do projeto. Alguns agricultores (C28, C41, C46, entre 
outros) informaram que alertaram a Secma que as lascas de teca não aguentariam mais do que dois anos. Tal prognóstico confirmou-se um ano após a distribuição das lascas, como se pode observar na Figura 4.

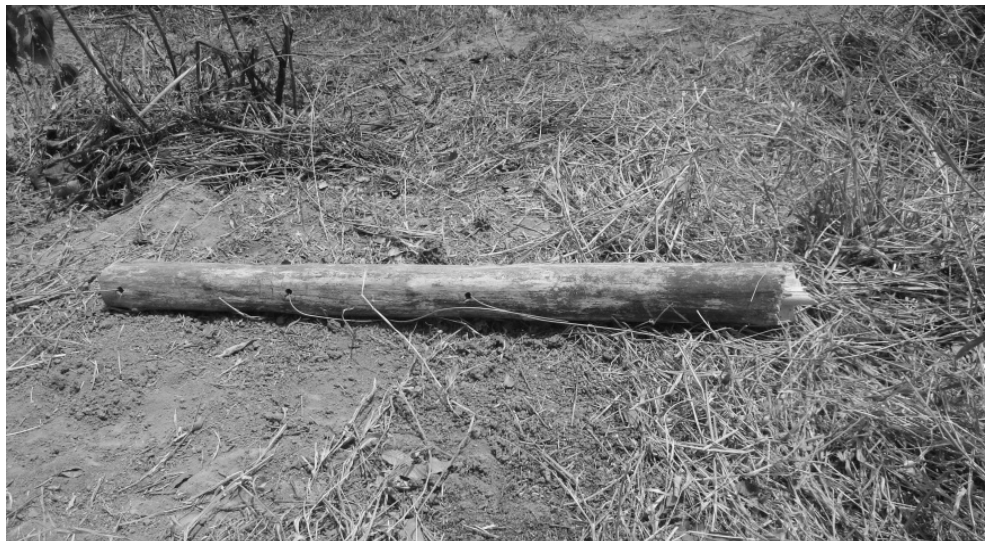

Figura 4 - Lasca de teca tombada na propriedade do agricultor C1. Alta Floresta-MT.

Onde: 1 - arame da cerca; 2 - lasca de teca tombada pelo apodrecimento.

Fonte: Acervo dos autores.

Essa situação deixou os agricultores preocupados, tendo em vista que assinaram o Termo de Ajustamento de Conduta (TAC) na Promotoria de Justiça do município comprometendo-se a cercar e recuperar as APPs.

Em maio de 2014 um grupo de agricultores preocupado com esse quadro buscou orientação e apoio da Secma e Ministério Público Estadual para resolver o problema, pois não tinha condições financeiras para comprar lascas para refazer as cercas das APPs que tombaram com as lascas de teca. Todavia, até a elaboração deste trabalho, nenhuma resposta havia sido dada aos agricultores. A intenção era receber lascas de itaúba para substituir as lascas de tecas apodrecidas, mesmo que fossem em menor quantidade.

O cenário indica que esses atores sociais mais uma vez amargaram pelos erros cometidos pelo setor público que em sua maioria não dialoga com os agricultores, pois continua vendo-os como meros objetos e não como sujeitos (FREIRE, 1980) não querendo reconhecer o conhecimento empírico acumulado dos agricultores. Em síntese, entre os atores sociais externos às comunidades ainda não há a cultura da prática do enfoque sistêmico, na expectativa de construir com os agricultores o desenvolvimento de forma sustentável.

As ações implementadas, conduzidas diretamente pela Secma e Promotoria de Justiça, poderiam ter obtido um alcance mais positivo, caso tivesse sido adotada uma comunicação horizontalizada com a participação ativa dos agricultores como protagonistas do processo, nas tomadas de decisão por meio da práxis construtivista (FREIRE, 1980) estimulando-os à adoção da visão coevolucionista nos agroecossistemas (NORGAARD, 1984; SEVILLA GUZMÁN, 2001).

Todavia, a revegetação das APPs ocorreu por uma decisão vertical aplicando, in continenti, a legislação ambiental por meio da convocação dos agricultores para assinatura do TAC pela Promotoria de Justiça. A forma como foi desencadeado esse processo gerou insatisfação, tendo em vista que $62,5 \%$ dos entrevistados consideraram que houve abuso de poder, conforme relato dos agricultores representados nas seguintes expressões: "[...] não precisava disso, produtores foram tratados como bandido [...] os produtores ficaram constrangidos [...] poderia ter feito reunião para explicar" (agricultor C2) e "a gente merece mais respeito, a gente deve ser tratado de uma forma mais respeitosa [...] não é que nós agricultores sejamos contra o meio ambiente, só que ele passa como rolo compressor em cima de todo mundo" (agricultor C37). 
A ação gerou insegurança e até medo em alguns agricultores, como relata o agricultor C18:

tive que colocar a teca no chão na seca passada, na base de um jogar água no buraco para outro furar [...] tive que fazê na seca porque tinha fiscalização direto e tínhamos que fazer, se não fizesse em 60 dias ia recolher o material; tínhamos medo porque a fiscalização era direto, uma pressão danada (grifo nosso).

Durante as entrevistas ficou evidenciado o receio e/ou medo da maioria dos agricultores quando as perguntas envolviam a questão ambiental, sobretudo quando o assunto era o TAC. Nesse caso, vários entrevistados informaram que não tinham conhecimento, principalmente aqueles que não haviam sido convocados pela Promotoria de Justiça, em uma clara demonstração de que não queriam se manifestar sobre o assunto, pois qualquer manifestação poderia gerar problemas para eles. Muitos agricultores (C15, C31, C21, C40, C45, C48 e C56) só externavam sua opinião quando o gravador era desligado.

\section{CONCLUSÕES E CONSIDERAÇÕES FINAIS}

A MBM encontra-se degradada social e ambientalmente como consequência da interação entre as variáveis pesquisadas cuja degradação dos recursos naturais (solo, floresta e mananciais) é oriunda da falta de condições econômicas dos agricultores para adotar o manejo correto dos solos devido à falta de participação social que vem contribuindo para a migração dos jovens para os centros urbanos e que afetará a reprodução social.

Diagnosticou-se também que os agricultores, em sua maioria, percebem que a recuperação das APPs é imprescindível, pois reconhecem a importância das matas ripárias no aumento e melhoria da qualidade da água e do ambiente da MBM. Todavia, ressaltam a necessidade da implementação de ações na construção de curvas de nível e terraços para conservação dos solos.

Defende-se que o poder público municipal precisa incorporar a MBM como um território a ser trabalhado urgentemente e de forma contínua, envolvendo os agricultores nas tomadas de decisões, como protagonistas do processo, por meio da práxis contínua de ações e atividades de Extensão Rural praticada pela Secretaria Municipal de Agricultura e de Meio Ambiente, empregando o princípio construtivista defendido por Paulo Freire.

Todavia se faz necessário que as famílias superem o individualismo, se unam e se organizem para galgarem melhores condições de enfrentamento e superação das dificuldades presentes no meio rural.

Entende-se que um estudo mais amplo envolvendo outras variáveis (fertilidade, permeabilidade e microbiota dos solos; qualidade de vida das famílias, entre outras) se faz necessário para se ter uma radiografia completa dos agroecossistemas da MBM na busca de implementação de políticas (públicas e/ou privadas) para o desenvolvimento sustentável daquele território.

\section{AGRADECIMENTOS}

À Universidade do Estado de Mato Grosso por liberar o primeiro autor para o doutorado, ao apoio financeiro e à Bolsa de Doutorado fornecida pela Fundação de Amparo à Pesquisa do Estado de São Paulo (Fapesp), à Capes (Coordenadoria de Aperfeiçoamento de Pessoal de Nível Superior) pela bolsa de doutorado sanduiche no exterior, à Profa. Me. Virgínia Neves Salles pela revisão textual do artigo e, especialmente, aos agricultores da Microbacia Hidrográfica Mariana que participaram da pesquisa.

\section{NOTAS}

${ }^{1}$ Trabalho oriundo de parte da tese de doutorado defendida em fevereiro de 2015 na Faculdade de Engenharia Agrícola da Universidade Estadual de Campinas, São Paulo.

${ }^{2} \mathrm{O}$ Portal Território da Amazônia, constituído por 16 municípios, está localizado no extremo norte do estado de Mato Grosso (MERTENS et al., 2011).

${ }^{3}$ Entorno refere-se à área localizada imediatamente após a APP. 
${ }^{4} \mathrm{O}$ Dr. J. Robert Tompkin, professor de Economia Rural de Ohio State University, e Técnico do convênio entre Usaid/B OSU-Esalq, ministrou cursos de Estatística Avançada no Departamento de Ciências Sociais da Escola Superior de Agricultura "Luiz de Queiroz", em Piracicaba.

${ }^{5}$ Doença transmitida pelo mosquito Anopheles spp que matou muitas pessoas na abertura do município e região.

\section{REFERÊNCIAS}

ABRAMOVAY, R.; MAGALHÃES, R.; SCHRODER, M. Representatividade e inovação na governança dos processos participativos: o caso das organizações brasileiras de agricultores familiares. Sociologias, Porto Alegre, ano 12, n. 24, p. 268-306, mai./ago. 2010.

ABREU, B. S. de. et al. Diagnóstico socioeconômico da microbacia hidrográfica. Riacho da Igreja, Cabaceiras/PB. Revista Educação Agrícola Superior, v. 26, n. 1, p. 25-29, 2011.

ALTA FLORESTA (Município). Agenda 21 de Alta Floresta. Plano de Intervenção em áreas alteradas. 2008,22 p. (Relatório).

Decreto n. 4.073, de 11 de julho de 2011. Dispõe sobre a execução de projetos ambientais e pagamento por serviços ambientais no âmbito da gestão ambiental municipal da Bacia Hidrográfica Mariana. 2011.8 p.

ARRAES, R. A.; MARIANO, F. Z.; SIMONASSI, A. G. Causas do desmatamento no Brasil e seu ordenamento no contexto mundial. Revista de Economia e Sociologia Rural, Piracicaba-SP, v. 50, n. 1, p. 119-140, jan./mar. 2012.

BARRIOS, J. L. G.; DESCROIX, L. Adaptación a la degradación de los recursos naturales en la Zona Semiárida Mexicana. Sustentabilidade em Debate, p. 114-126, 2010.

BECKER, B. K. Amazônia. Rio de Janeiro: Ática Garamond, 1998. 112 p.

BERNASCONI, P. et al. Avaliação da resiliência do sistema socioecológico de médias e grandes propriedades rurais de Cotriguaçu (MT, Brasil). Sustentabilidade em Debate, Brasília, v. 7, n. 2, p. 53-72, mai./ago. 2016.

BOURDIEU, P. A economia das trocas simbólicas. São Paulo: Perspectiva, 1974.

BRASIL. Presidência da República. Lei 12.188, de 11 de janeiro de 2010. Institui a Política Nacional de Assistência Técnica e Extensão Rural - Pnater. 5 p.

Presidência da República. Lei n. 11.326, de 24 de julho de 2006. Formulação da Política Nacional da Agricultura Familiar. Diário Oficial da União, n. 141, Seção 1, de 25 de jul. de 2006.

CECONI, D. E. Diagnóstico e recuperação da mata ciliar da sanga Lagoão do Ouro na microbacia hidrográfica do Vacacaí-mirim, Santa Maria - RS. 132p. Tese (Doutorado em Ciência do Solo) - Centro de Ciências Rurais, Universidade Federal de Santa Maria, 2010.

COSTA, E. M. da. et al. Matéria orgânica do solo e o seu papel na manutenção e produtividade dos sistemas agrícolas. Enciclopédia Biosfera: Goiânia, v. 9, n. 17; p. 1.842-1860, 2013.

EMPRESA BRASILEIRA DE PESQUISA AGROPECUÁRIA. Manual de métodos de análise de solo. Rio de Janeiro: Embrapa Solos. 1997. 212 p.

FRANZLUEBBERS, A. J. Soil organic matter stratification ratio as an indicator of soil quality. Soil Till. Res., v. 66, p. 95-106, 2002.

FREIRE, P. Extensão ou comunicação? Rio de Janeiro: Paz e Terra, 1980. 93 p.

GALLOPÍN, G. C. Sostenibilidad y desarrollo sotenible: um enfoque sistémico. Santiago do Chile: Cepal, 2003. 44 p.

GIAROLA, N. F. B.; TORMENA, C. A.; DUTRA, A. C. Degradação física de um Latossolo Vermelho utilizado para produção intensiva de forragem. Revista Brasileira de Ciência do Solo, n. 31, p. 863-873, 2007.

INSTITUTO BRASILEIRO DE GEOGRAFIA E ESTATÍSTICA. Estatísticas do meio rural. 2. ed. Brasília: MDA/Dieese, 2006. 276 p. 
População 2010: censo demográfico 2010. Disponível em: <http://www.cidades.ibge.gov.br/xtras/ temas.php?lang=\&codmun=510025\&idtema=1\&search=mato-grosso|alta-floresta |censo-demografico-2010:sinopse->. Acesso em: 20 mai. 2016.

MEIHY, J. C. S. B.; RIBEIRO, S. L. S. Guia prático de história oral: para empresas, universidades, comunidades, famílias. São Paulo: Contexto, 2011. 198 p.

MERTEN, G. H.; MINELLA, J. P. Qualidade da água em bacias hidrográficas rurais: um desafio atual para a sobrevivência futura. Agroecologia e Desenvolvimento Rural Sustentável, v. 3, n. 4, p. 33-38, 2002.

MERTENS, F. et al. Redes sociais, capital social e governança ambiental no Território Portal da Amazônia. Acta Amazônica, v. 41, n. 4, p. 481-492, 2011.

NEUMANN, P. S.; LOCH, C. Legislação ambiental, desenvolvimento rural e práticas agrícolas. Ciência Rural, Santa Maria, v. 32, n. 2, p. 243-249, 2002.

NORGAARD, R. B. Coevolutionary development potential. Land Economics, v. 60, n. 2, mayo, p. 160-173, 1984. (versão em espanhol, traduzida por María Isabel Núñez Vera e Federico Aguilera Klink).

OLIVAL, A. A. A resiliência em assentamentos rurais: uma experiência na região norte de Mato Grosso. Sustentabilidade em Debate, Brasília, v. 7, n. 2, p. 90-103, mai./ago. 2016.

OLIVEIRA, H.; URCHEI, M. A.; FIETZ, C. R. Aspectos físicos e socioeconômicos da Bacia Hidrográfica do Rio Ivinhema. Dourados: Embrapa Agropecuária Oeste, 2000. 52 p.

PETEAN, L. P.; TORMENA, C. A.; ALVES, S. J. Intervalo hídrico ótimo de um Latossolo Vermelho distroférrico sob plantio direto em sistema de integração lavoura-pecuária. Revista Brasileira de Ciência do Solo, v. 34, n. 5, p. 1515-1526, 2010.

REICHERT, J. M.; SUZUKI, L. E. A. S.; REINERT, D. J. Compactação do solo em sistemas agropecuários e florestais: identificação, efeitos, limites críticos e mitigação. Tópicos Ciência do Solo, v. 5, p. 49-134, 2007.

RICHARDSON, R. J. et al. Pesquisa Social: métodos e técnicas. São Paulo: Atlas, 1999. 334 p.

ROBOREDO, D.; BERGAMASCO, S. M. P. P.; BLEICH, M. E. Aggregate index of social -environmental sustainability to evaluate the social-environmental quality in a watershed in the Southern Amazon. Ecological Indicators, v. 63, p. 337-345, 2016.

RODRIGUEZ, N. V.; COSTA, P. D.; SERRANO, M. M. El mejoramiento de los agroecosistemas comienza por el suelo: un caso de iniciativa local. Leisa Revista de Agroecología, v. 24, n. 2, p. 21-23, 2008.

SEVILLA-GUZMÁN, E. Bases sociológicas de la agroecología. In: ENCONTRO INTERNACIONAL SOBRE AGROECOLOGIA E DESENVOLVIMENTO RURAL SUSTENTÁVEL. Faculdade de Ciências Agronômicas. Universidade Estadual Paulista, Campus de Botucatu. 5-8 de julho de 2001.

SILVA JÚNIOR, R. F. da. Eliminação de barreiras: produção de fluidez e circulação no Brasil. Revista Formação, Edição Especial, Presidente Prudente, v. 2, n. 13, p. 29-41, 2006.

STOLF, R. Teoria e teste experimental de fórmulas de transformação dos dados de penetrômetro de impacto em resistência do solo. Revista Brasileira de Ciência do Solo, Viçosa, v. 15, p. 229-235, 1991.

TOMPKIN, J. R. Estatística e métodos de pesquisa em ciências sociais rurais. Piracicaba: Escola Superior de Agricultura Luiz de Queiroz, 1967. 174 p.

UMETSU, R. K. Estudo eco-hidrológico da bacia hidrográfica Mariana, afluente do Rio Taxidermista, Alta Floresta - MT. 116p. Tese (Doutorado em Ciências) - Universidade Federal de São Carlos, São Carlos, 2009.

WANDERLEY, M. N. B. O mundo rural como um espaço de vida: reflexões sobre a propriedade da terra, agricultura familiar e ruralidade. Porto Alegre: UFRGS, 330 p. 2009.

ZOBY, J. L. G.; OLIVEIRA, F. R. de. Panorama da qualidade das águas subterrâneas no Brasil. Brasília: ANA, 80 p., 2005 . 